\title{
The Short-Term Effect of Breathing Tasks Via an Incentive Spirometer on Lung Function Compared With Autogenic Drainage in Subjects With Cystic Fibrosis
}

\author{
Gil Sokol, Daphna Vilozni PhD, Ran Hakimi, Moran Lavie MD, Ifat Sarouk MD, Bat-El Bar MD, \\ Adi Dagan MD, Miryam Ofek MD, and Ori Efrati MD
}

\begin{abstract}
BACKGROUND: Forced expiration may assist secretion movement by manipulating airway dynamics in patients with cystic fibrosis (CF). Expiratory resistive breathing via a handheld incentive spirometer has the potential to control the expiratory flow via chosen resistances $(1-8 \mathrm{~mm})$ and thereby mobilize secretions and improve lung function. Our objective was to explore the short-term effect of using a resistive-breathing incentive spirometer on lung function in subjects with $\mathbf{C F}$ compared with the autogenic drainage technique. METHODS: This was a retrospective study. Subjects with CF performed 30-45 min of either the resistive-breathing incentive spirometer $(n=$ 40) or autogenic drainage $(n=32)$ technique on separate days. The spirometer encourages the patient to exhale as long as possible while maintaining a low lung volume. The autogenic drainage technique includes repetitive inspiratory and expiratory maneuvers at various tidal breathing magnitudes while exhalation is performed in a sighing manner. Spirometry was performed before and 20-30 min after the therapy. RESULTS: Use of a resistive-breathing incentive spirometer improved FVC and $\mathrm{FEV}_{1}$ by $5-42 \%$ in 26 subjects. The forced expiratory flow during the middle half of the FVC maneuver $\left(\mathrm{FEF}_{25-75 \%}\right)$ improved by $>20 \%$ in $9(22 \%)$ subjects. FVC improved the most in subjects with an $\mathrm{FEV}_{1}$ of 40-60\% of predicted. Improvements negatively correlated with baseline percent-of-predicted FVC values provided improvements were above $10 \%\left(r^{2}=0.28\right)$. Values improved in a single subjects using the autogenic drainage technique. CONCLUSIONS: These 2 techniques may allow lower thoracic pressures and assist in the prevention of central airway collapse. The resistive-breathing incentive spirometer is a self-administered simple method that may aid airway clearance and has the potential to improve lung function as measured by FVC, $\mathbf{F E V}_{\mathbf{1}}$, and $\mathbf{F E F}_{\mathbf{2 5 - 7 5} \%}$ in patients with CF. Key words: respiratory physiotherapy; cystic fibrosis; lung function. [Respir Care 2015;60(12):1819-1825. (C) 2015 Daedalus Enterprises]
\end{abstract}

\section{Introduction}

Cystic fibrosis (CF) is a disorder that interrupts the lungs' normal mucus secretion, causing excessive production of

\footnotetext{
The authors are affiliated with the Pediatric Pulmonary Unit and the Cystic Fibrosis National Center, The Edmond and Lily Safra Children's Hospital, Sheba Medical Center, Ramat-Gan, affiliated with the Sackler Medical School, Tel Aviv University, Tel Aviv, Israel.
}

The study was supported by the J Baum Foundation of the Israel Lung Association (Tel Aviv, Israel).

Correspondence: Daphna Vilozni PhD, Pediatric Pulmonary Unit, The Edmond and Lily Safra Children's Hospital, Sheba Medical viscid mucus, which leads to mucus plugging, recurrent infections, and inflammation, followed by airway damage and lung function deterioration. ${ }^{1-3}$ Airway clearance therapy aims to improve mucociliary clearance through the removal of tenacious obstructing mucus from the airways, thus improving ventilation. ${ }^{3-5}$ Indeed, Cochrane reviews ${ }^{1,5-7}$ have concluded that airway clearance techniques have the short-term effect of increasing mucus transport, and there

Center, Ramat-Gan, Israel, affiliated with the Sackler Medical School, Tel Aviv University, Tel Aviv 52621, Israel. E-mail: daphna.vilozni@sheba.health.gov.il.

DOI: $10.4187 /$ respcare. 04008 
appears to be no advantage of either conventional chest physiotherapy or oscillating devices over other airway clearance techniques in the primary outcome measure of lung function.

Autogenic drainage to mobilize secretions ${ }^{8}$ is a respiratory self-drainage technique that uses controlled tidal breathing performed at different lung volume levels. In this technique, the velocity or force of the expiratory air flow must be self-adjusted at each level of inspiration so that the highest possible air flow is reached in that generation of bronchi without causing airway collapses during coughing. Although the autogenic drainage technique was found to be useful in mobilizing and diluting secretions and improving oxygen saturation, lung function improvements could not be demonstrated. ${ }^{6}$

Handheld devices using expiratory air-flow exercises through fixed resistance may motivate patients to increase self-management of their condition. ${ }^{9-14}$ Such devices include oscillatory positive expiratory pressure (PEP) devices, which produce air-flow oscillations in addition to PEP. Studies have shown that the PEP technique improved lung volumes and expiratory flow when used over a 1012-month period, but no immediate effect on lung function was found. ${ }^{9-14}$

A handheld incentive spirometer is designed to encourage patient inhalation by slow deep breaths while providing the patient with information that helps maintain an inhaled lung volume. This device, without the resistance, is widely used after upper abdominal operations accompanied by postoperative pulmonary complications, and has been shown to improve sputum expectoration. ${ }^{15,16} \mathrm{An}$ advanced incentive spirometer includes the possibility of performing long expirations against a chosen resistance level (resistive-breathing incentive spirometer). Thus, it may be used for respiratory physical therapy in patients with CF. The aim of this study was to explore the effect of using a resistive-breathing incentive spirometer for airway clearance by considering the short-term effect on lung function in subjects with $\mathrm{CF}$.

\section{Methods}

\section{Subjects}

Data were acquired from subjects with $\mathrm{CF}$ who routinely visited the ambulatory clinic in our center. The diagnosis of CF was made by the presence of at least one typical clinical manifestation of the disease combined with an abnormal sweat test (chloride $>60 \mathrm{mmol} / \mathrm{L}$ ) and/or the presence of CF mutations.

We recruited subjects with CF ( $>8$ y old) who visited the CF clinic for their routine follow-ups (once in 2-3 months) over $1 \mathrm{y}$, and we performed pulmonary function tests before and 20-30 min after the therapy session. Sub-

\section{QUICK LOOK}

\section{Current knowledge}

Cystic fibrosis (CF) interrupts the lungs' normal mucus secretion, causing excessive production of viscid mucus, which leads to mucus plugging, recurrent infections, and inflammation, followed by airway damage and lung function deterioration. Airway clearance therapy aims to improve mucociliary clearance, lung function, and quality of life. To date, research has shown that airway clearance techniques have the short-term effect of increasing mucus transport, and there appears to be no advantage of either conventional chest physiotherapy or oscillating devices over other airway clearance techniques.

\section{What this paper contributes to our knowledge}

This retrospective study of expiratory resistive breathing via a handheld incentive spirometer compared with autogenic drainage in subjects with $\mathrm{CF}$ demonstrated improved lung function following resistive-breathing incentive spirometer use. Both $\mathrm{FVC}$ and $\mathrm{FEV}_{1}$ improved in more than half of subjects studied. These changes are temporal, and the impact on long-term outcomes are not known.

jects in a stable clinical condition had to be familiar with pulmonary function tests and respiratory therapy clearance techniques. Patients who were on oxygen or home intravenous therapy or who had current pulmonary exacerbations or hospitalizations were excluded. Otherwise, the study did not require changes in medication or lifestyle. All participants were familiar with the use of the autogenic drainage technique for airway clearance as a daily treatment, but not with the resistive-breathing incentive spirometer, which was introduced in the physiotherapy session. The Helsinki Board of Sheba Medical Center approved the study (5583-08-SMC).

\section{Study Design}

This was a retrospective study performed from 2008 to 2011. All data selected for inclusion in this retrospective study were obtained from subjects who performed spirometry before and after airway clearance therapy, regardless of the technique applied. All subjects performed the autogenic drainage technique regularly on clinic visits. The resistive-breathing incentive spirometer technique was introduced to all subjects, and most elected to continue performing it on a regular basis in clinical visits during the study period. We sought to compare the effect of every 


\section{Exhalation Tasks and Lung Function IN CF}

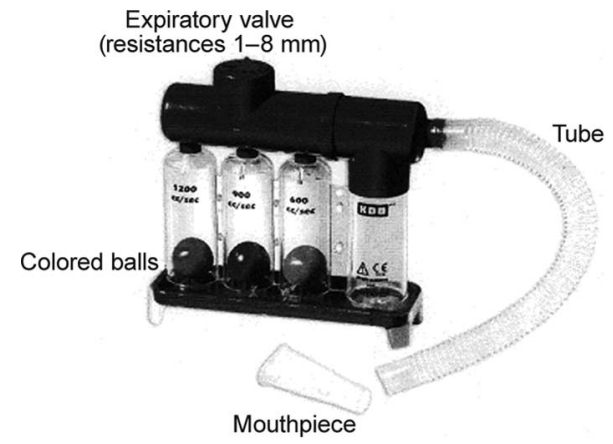

Fig. 1. The Tri-Gym handheld device.

intervention on spirometry measurements for each subject on both techniques.

The physiotherapy sessions did not require changes in medication or life style. After initially performing a baseline lung function test, subjects underwent a respiratory exercise session using one of the 2 methods (resistivebreathing incentive spirometer or autogenic drainage). Twenty to $30 \mathrm{~min}$ after physiotherapy ceased, the lung function test was repeated. Both respiratory therapy sessions were coached by the same respiratory therapist.

\section{Interventions}

The Tri-Gym (Koo Asia, Tsuen Wan, Hong Kong) (Fig. 1) is a handheld volumetric breathing exerciser consisting of 3 graduated cylinders, each containing a differently colored ball. The volumetric target goals are 600, 900, and $1,200 \mathrm{~mL} / \mathrm{s}$. A corrugated tube with a mouthpiece is connected to the superior lateral part of the device. An adjustable valve with tiny openings from 1 to $8 \mathrm{~mm}$ in diameter is placed at the opening of the device to control the expiratory breathing resistance.

With a resistive-breathing incentive spirometer, the breathing maneuvers are similar to those used in the autogenic drainage technique, but the breathing effort is resistance-dependent. Breathing tasks were performed in a sitting position. Subjects held the breathing device in a position that allowed expiratory resistive breathing. They were then asked to seal their mouths around the mouthpiece. When relaxed, subjects were asked to inhale to total lung capacity and exhale as much as possible once or twice to the point where tidal breaths at low lung volume could be performed against a chosen resistance. The level of resistance was selected in relation to the ability of each subject to maintain the volumetric ball at a target volume for as long as possible (to allow time for the air to get behind the mucus). If resistance was too high to maintain the ball at the target level (expiratory flow was too low), it was lowered. Conversely, if the duration of expiration was too short, resistance was increased. In addition, the visual feedback (ascending balls) increased motivation. The physiotherapist stood behind the subject and pressed the sternum to help sustain expiration. Huff-coughs were performed at various lung volumes above residual volume via the chosen resistance until the final cough when mucus was cleared. The breathing exercise was repeated until subjects felt a need to cough, and then $2-3$ forced huffs were performed via the Tri-Gym while removing the resistance. If the 3 balls in the Tri-Gym were elevated to maximum during the huff, the huff was considered successful. Cough was spontaneous, and then several forced huffs were performed to remove the mucus. The entire procedure was repeated several times for 20-30 $\mathrm{min} / \mathrm{session}$.

The autogenic drainage technique is well established. ${ }^{17}$ It includes repetitive inspiratory and expiratory maneuvers at various tidal breathing magnitudes with a pause of at least $3 \mathrm{~s}$ between inhalations and exhalations. Breathing out is performed in a sighing manner. The pause allows time for the air to get behind the mucus to evacuate it by a subsequent huff. One cycle of 3 phases typically lasts 1-4 min and is repeated until the preset autogenic drainage treatment time of $30 \mathrm{~min}$ has elapsed.

Forced expiratory flow-volume maneuvers were performed with the KoKo spirometer (nSpire Health, Longmont, Colorado) according to American Thoracic Society/European Respiratory Society standards. ${ }^{16}$ An experienced pulmonary technician instructed subjects how to perform the flow-volume maneuver. Emphasis was placed on full inspiration before expiration, without breath-holding, and on forced expiration to residual volume according to recommendations.

\section{Lung Function Data Analysis}

The best curves $\left(\mathrm{FVC}+\mathrm{FEV}_{1}\right)$ before and after the breathing therapies were analyzed. The following lung function indexes were analyzed: $\mathrm{FVC}, \mathrm{FEV}_{1}$, peak expiratory flow (PEF), and the forced expiratory flow during the middle half of the FVC maneuver $\left(\mathrm{FEF}_{25-75 \%}\right)$. The Student paired $t$ test was used (1) to find significant differences before and after breathing exercises determined by the percentage change from baseline for each lung function index and (2) to test the effect of each method on the same subject. A change of $<10 \%$ for $\mathrm{FVC}, \mathrm{FEV}_{1}$, or $\mathrm{PEF}$ and a change of $\leq 20 \%$ for $\mathrm{FEF}_{25-75 \%}$ were considered significant. The effects of the breathing exercises on lung function was correlated with sex, age, and pulmonary disease severity. $P<.05$ was considered significant.

\section{Results}

Forty subjects with CF (23 males) were enrolled in the study and performed the resistive-breathing incentive spi- 


\section{Exhalation Tasks and Lung Function in CF}

Table 1. Anthropometric Data and Basic Lung Function of Subjects

\begin{tabular}{|c|c|c|c|}
\hline & $\begin{array}{l}\text { Resistive Breathing } \\
\text { Incentive Spirometer } \\
\quad(n=40)\end{array}$ & $\begin{array}{l}\text { Autogenic Drainage } \\
\text { Technique }(n=32)\end{array}$ & $P$ \\
\hline Males/Females, $n$ & $23 / 17$ & $20 / 12$ & .89 \\
\hline Age, y & $26.1 \pm 8.6$ & $20.9 \pm 7.9$ & .13 \\
\hline BMI, $\mathrm{kg} / \mathrm{m}^{2}$ & $19 \pm 3$ & $20.9 \pm 2.6$ & .02 \\
\hline \multicolumn{4}{|l|}{$\begin{array}{r}\text { Spirometry, \% } \\
\text { predicted }\end{array}$} \\
\hline FVC & $71 \pm 21$ & $82 \pm 20$ & .06 \\
\hline $\mathrm{FEV}_{1}$ & $57 \pm 21$ & $66 \pm 22$ & .07 \\
\hline PEF & $62 \pm 22$ & $76 \pm 22$ & .09 \\
\hline $\mathrm{FEF}_{25-75 \%}$ & $39 \pm 27$ & $42 \pm 29$ & .57 \\
\hline $\begin{array}{l}\mathrm{BMI}=\text { body mass index } \\
\mathrm{PEF}=\text { peak expiratory flow }\end{array}$ & $\begin{array}{l}\text { w } \\
\text { tory flow during the middle ha }\end{array}$ & of the FVC maneuver & \\
\hline
\end{tabular}

Table 2. Effect of Therapy Method on Lung Function

\begin{tabular}{lccc}
\hline \hline $\begin{array}{c}\text { Spirometry } \\
\text { Parameter }\end{array}$ & $\begin{array}{c}\text { Resistive Breathing } \\
\text { Incentive Spirometer }\end{array}$ & $\begin{array}{c}\text { Autogenic Drainage } \\
\text { Technique }\end{array}$ & $\begin{array}{c}P \\
\text { (Between } \\
\text { Methods) }\end{array}$ \\
\hline FVC & $11 \pm 10(7-14)$ & $3 \pm 6(1-6)$ & $<.001$ \\
$\mathrm{FEV}_{1}$ & $10 \pm 12(6-14)$ & $2 \pm 5(-1.0$ to 3$)$ & $<.001$ \\
$\mathrm{PEF}$ & $10 \pm 19(3-16)$ & $0 \pm 11(-4$ to 4$)$ & .039 \\
$\mathrm{FEF}_{25-75 \%}$ & $6 \pm 23(-2$ to 13$)$ & $-1 \pm 12(-5$ to 4$)$ & .34
\end{tabular}

Values are expressed as mean \pm SD $\%$ change from baseline $(95 \% \mathrm{CI})$.

$\mathrm{PEF}=$ peak expiratory flow

$\mathrm{FEF}_{25-75 \%}=$ forced expiratory flow during the middle half of the FVC maneuver

rometer technique. No adverse events were provoked by breathing through the spirometer; however, 8 subjects complained of transient exhaustion, which disappeared a few minutes after completion of physiotherapy. Eighty-five percent of the subjects reported that they would use the device at home. Thirty-two of 40 subjects also performed the autogenic drainage technique on a different day. The anthropometric data and basic lung function for all subjects are presented in Table 1. There was no significant difference between the groups regarding anthropometric data or baseline lung function.

The short-term effect of the therapy method on lung function (\% change from baseline) with regard to each of the spirometry parameters is presented in Table 2. Use of the resistive-breathing incentive spirometer resulted in a significant increase in FVC, $\mathrm{FEV}_{1}$, and PEF $(P<.001$, $P<.001$, and $P=.009$, respectively). The $\mathrm{FVC}$ and $\mathrm{FEV}_{1}$ of 26 of 40 subjects improved by $5-42 \%$. Mid-flows improved by $>20 \%$ in $9(23 \%)$ subjects. The use of the autogenic drainage technique did not lead to a significant increase in either of these parameters.

The number of subjects (\% of population) with improvements in FVC, $\mathrm{FEV}_{1}$, or $\mathrm{PEF}$ of $\geq 10 \%$ or
Table 3. Number of Subjects and Proportion of Population Who Showed Improvement in Lung Function

\begin{tabular}{lcccc}
\hline \hline & $\begin{array}{c}\text { Change From } \\
\text { Baseline, } \\
\%\end{array}$ & $\begin{array}{c}\text { Resistive Breathing } \\
\text { Incentive } \\
\text { Spirometer, } \\
n(\%)\end{array}$ & $\begin{array}{c}\text { Autogenic } \\
\text { Drainage } \\
\text { Technique, } \\
n(\%)\end{array}$ & $\begin{array}{c}P \\
\text { (Between } \\
\text { Methods) }\end{array}$ \\
\hline Improvement & & & & \\
FVC & $>10$ & $17(43)$ & $5(16)$ & .02 \\
FEV $_{1}$ & $>10$ & $11(28)$ & $1(3)$ & $<.001$ \\
PEF & $>10$ & $16(40)$ & $3(9)$ & .01 \\
FEF $_{25-75 \%}$ & $>20$ & $9(23)$ & $2(6)$ & .10 \\
Deterioration & & & & \\
FVC & $<-10$ & 0 & 0 & .99 \\
FEV $_{1}$ & $<-10$ & 0 & $3(9)$ & .08 \\
PEF $_{\text {FEF }}$ & $<-10$ & 0 & $3(9)$ & .08 \\
& $<-20$ & $3(8)$ & $3(9)$ & .08
\end{tabular}

PEF $=$ peak expiratory flow

$\mathrm{FEF}_{25-75 \%}=$ forced expiratory flow during the middle half of the $\mathrm{FVC}$ maneuver

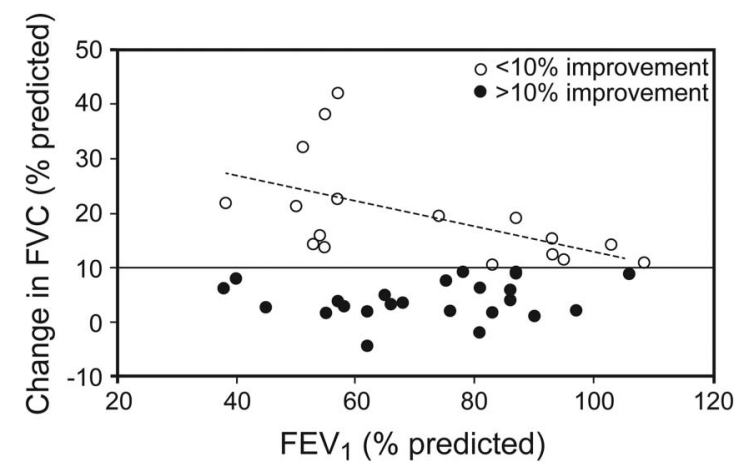

Fig. 2. Correlation between baseline percent-of-predicted FVC and improvements in percent-of-predicted $\mathrm{FEV}_{1}$ after resistive breathing via a handheld spirometer.

$\mathrm{FEF}_{25-75 \%}$ of $\geq 20 \%$ above baseline is presented in $\mathrm{Ta}-$ ble 3 for both methods. The number of subjects with improvements in FVC, $\mathrm{FEV}_{1}$, and PEF was significantly greater when exercising with the resistive-breathing incentive spirometer. We also found that the spirometer may improve FVC by $>10 \%$ above baseline at any $\mathrm{FEV}_{1}$ level.

The correlation between baseline percent-of-predicted FVC and improvements after resistive-breathing incentive spirometer therapy is presented in Figure 2. Subjects with an $\mathrm{FEV}_{1}$ of $40-60 \%$ of predicted had the greatest improvement in FVC. Improvements demonstrated a negative correlation with baseline percent-of-predicted FVC once improvement was above $10 \%\left(\mathrm{r}^{2}=0.28\right)$. Results were similar for $\mathrm{FEV}_{1}$ and PEF (data not shown). FVC improved significantly more in females than males (13.9 \pm 10.6 vs $8.2 \pm 9.5, P=.042$ ). Improvements in other indexes concerning sex were similar. 


\section{Exhalation Tasks and Lung Function IN CF}

\section{Discussion}

In this study, we investigated the short-term effect of expiratory resistive breathing via an incentive spirometer on lung function in a large group of subjects with CF. Our main findings show that use of the resistive-breathing incentive spirometer significantly elevated lung function and especially FVC values in one third of our subjects when measured within 20-30 min after the therapy session, especially when FVC was $40-60 \%$ of predicted. We found that the resistive-breathing incentive spirometer technique was well accepted with no adverse events, and the majority of subjects reported that they would use the device at home.

The immediate effect of respiratory physiotherapy is the movement of mucus toward central airways. This may cause a transient obstruction that may negatively alter lung function. It is therefore important to establish the peakeffect time for measuring post-treatment lung function. We measured lung function 20-30 min after resistivebreathing incentive spirometer therapy. This duration is in agreement with the best time for post-therapy measurements in adults with $\mathrm{CF}$ as demonstrated by $\mathrm{FEV}_{1}{ }^{18}$

Our most interesting finding may be the greater improvement in FVC compared with $\mathrm{FEV}_{1}$. The ability to improve $\mathrm{FVC}$ was greater in subjects with a baseline $\mathrm{FEV}_{1}$ of $40-60 \%$ of predicted. Our findings may be explained by the fact that these subjects may still have parenchymal reserves and thus possess the ability to improve their lung function in moderate lung disease. Because $\mathrm{FEF}_{25-75 \%}$ is FVC- dependent, changes in $\mathrm{FEF}_{25-75 \%}$ may be concealed. Changes in $\mathrm{FEV}_{1}$ may also be concealed if collapse occurs during forced expiration. In that respect, we hypothesize that patients with CF and airway collapse may show improvement in lung function if they perform spirometry against an expiratory resistance such as that used in the resistive-breathing incentive spirometer physiotherapy session. We found that subjects with very low percent-ofpredicted $\mathrm{FEV}_{1}$ did not improve as much as subjects with an $\mathrm{FEV}_{1}$ of $40-60 \%$ of predicted, who showed improvements of $>10 \%$. Our findings were similar to those presented by Placidi et al, ${ }^{20}$ who studied short-term changes in $\mathrm{FEV}_{1}$ and $\mathrm{FEF}_{25-75 \%}$ after positive airway pressure therapy in 17 subjects with $\mathrm{CF}$ and severe airway obstruction $\left(\mathrm{FEV}_{1}<40 \%\right.$ predicted). They did not find any significant effect of this technique on lung function. It should be noted that $25 \%$ of our population with severely reduced $\mathrm{FEV}_{1}$ decreased their $\mathrm{FEF}_{25-75 \%}$ by $>20 \%$ after our resistive-breathing incentive spirometer therapy. We suggest that these findings may indicate the movement of secretions toward central airways and even blocked flow in the small airways and therefore may be expressed as a reduction in $\mathrm{FEF}_{25-75 \%}$. This suggestion is supported by Chatham et al, ${ }^{22}$ who found that resistive breathing led to increased expectoration of sputum from the periphery to central airways. In our study, the incidence of females improving their lung function was higher compared with males. The incidence of severe obstruction was also greater in females than in males. This finding could partially explain the greater incidence of significant post-treatment improvements in females. In our study, the autogenic drainage technique did not increase the short-term measurements of lung function, as was found previously for the long-term effect. ${ }^{17}$

Theoretically, the resistive-breathing incentive spirometer may have several advantages compared with other handheld devices. It is well established that performing expiration via resistance allows air to get behind the mucus, which is essential for mucus clearance to occur. ${ }^{21-23} \mathrm{In}$ our study, we chose the expiratory resistance applied at the mouth that was able to initiate the longest expiration with the highest flow. In return, this chosen resistance may have resulted in a positive pressure sufficient to have been transmitted to the airways, thus holding the airways open during expiration in an optimally controlled fashion. The increased airway pressure during expiration (PEP) is thought to be useful in pushing air through collateral pathways into distal lung units beyond the retained secretions, along with preventing early airway closure, prolonging expiration, and promoting movement of secretions toward central airways. ${ }^{14}$

All handheld devices employ resistive-breathing techniques. ${ }^{10}$ The PEP technique suggests that the target resistance should be between 10 and $20 \mathrm{~cm} \mathrm{H}_{2} \mathrm{O}$ during mid-expiration measured by a manometer. With the Flutter device (Axcan Scandipharm, Birmingham, Alabama), the PEP and cyclic oscillation (airway vibration) are produced by lifting a gravity-dependent ball and sustaining it in the air. The Acapella device (Smiths Medical, Watford, United Kingdom) comes in 3 models: low flow $(<15 \mathrm{~L} / \mathrm{min})$, high flow $(>15 \mathrm{~L} / \mathrm{min})$, and a dial that sets expiratory resistance. Indeed, these devices were proven to be effective in subjects with mild-to-moderate airway obstruction. ${ }^{22}$ Still, improvements in lung function were not found. It has been demonstrated that the very high and turbulent flow created by using the Flutter or Acapella instrument may cause early closure of the peripheral airways, ${ }^{22}$ which may in turn hamper immediate improvements in lung function. Moreover, in exhausted CF patients with severe lung disease, the ability to initiate and build a high flow behind the secretions may be impaired. We suggest that the main advantage of the resistive-breathing incentive spirometer is the ability to adjust resistance through the use of $1-8-\mathrm{mm}$ holes, allowing the operator to choose the desired expiratory resistance. This feature may provide greater opportunities for younger children to use a resistive-breathing incentive spirometer. 
Coughing is the body's way of removing mucus from the lungs. However, coughing is not always sufficient to clear the mucus, as hard coughing may lead to airway collapse. The huff-cough is a gentle cough that speeds air flow while keeping the throat open. Indeed, the huff-cough clears airways as effectively as a voluntary cough. ${ }^{3}$ However, the potential for substantial airway collapse, especially in the smaller bronchioles, still exists, especially because of cartilage damage in diseases such as $\mathrm{CF}$ and chronic bronchitis. We suggest that both the visual feedback provided by the ascension of the colored balls and the controlled PEP created by the adequate resistance enable the initiation of huff-coughs, a less injurious, semiforced expiration maneuver at low lung volumes. Furthermore, effective huffs at low lung volumes may improve mobilization of secretions even in decimated lung airways. Indeed, $25 \%$ of subjects with severely reduced $\mathrm{FEV}_{1}$ decreased their $\mathrm{FEF}_{25-75 \%}$ by $>20 \%$ after using our method. This suggestion is supported by Chatham et al, ${ }^{22}$ who found that resistive breathing led to increased expectoration of sputum from the periphery to central airways.

Finally, enhancing motivation is a great challenge in the treatment of patients with CF. ${ }^{21}$ The results of our study demonstrate that both immediate (within $<30 \mathrm{~min}$ ) and significant (slower) improvements in pulmonary function testing may greatly increase adherence. Most of our subjects said that they will continue to use this method for airway clearance. In a survey among adults, ${ }^{22}>50 \%$ of subjects believed that chest physiotherapy was not effective because they did not see an immediate improvement in lung function. A full chest physiotherapy session takes a minimum of $45 \mathrm{~min}$ to $1 \mathrm{~h} .{ }^{23}$ Such a long duration decreases adherence to treatment and increases opposition by older patients and especially by younger patients. ${ }^{24-26}$

\section{Study Limitations}

The final resistance level that each subject used with the Tri-Gym was not documented. Each subject chose the resistance level that provided an appropriate flow. Furthermore, we could not establish the reasons why subjects preferred a specific effort. We assume that the resistance per individual may change with the severity of the disease and with the amount/thickness/viscosity of the secretions. The actual PEP needed to lift a single ball to a sustained target of $600 \mathrm{~mL} / \mathrm{s}$ (or any other combination) is not provided in the manual for the device, and we do not know of any study in the literature concerning the expiratory pressure needed for these tasks when using the resistivebreathing incentive spirometer. However, the Tri-Gym is a well-known device used around the world for airway clearance therapy after surgery, so it is presumed to fit the standards. ${ }^{27}$
We did not measure the amount and weight of sputum obtained after resistive-breathing incentive spirometer therapy or compare the amount of sputum induced by this technique versus other techniques. However, the significant increases in $\mathrm{FVC}, \mathrm{FEV}_{1}$, and PEF provide objective evidence of improvements that occur after breathing through the modified resistive-breathing incentive spirometer method in subjects with CF. Furthermore, it is important to follow up on the long-term effect of this procedure on lung function deterioration. Such follow-up was beyond the scope of this study.

\section{Conclusions}

The incentive volumetric spirometer combined with variable resistance, expiration, and huffs with variable volume offers a unique but simple, friendly, and self-administered method of airway clearance in subjects with CF. We believe that the resistive-breathing incentive spirometer technique has 3 advantages over former handheld devices that enable short-term improvements in lung function. These include approximation of flow passing through an adequate choice of resistance, immediate visual feed-back of ascending colored balls, and the capacity to allow huffs at low lung volumes above the residual volume. The technique has been shown to improve $\mathrm{FVC}$ and $\mathrm{FEV}_{1}$, with PEF improving immediately after treatment. Further studies with a larger group of subjects are needed to confirm our findings.

\section{REFERENCES}

1. van der Schans C, Prasad A, Main E. Chest physiotherapy compared to no chest physiotherapy for cystic fibrosis. Cochrane Database Syst Rev 2000;(2):CD001401.

2. Konstan MW, Berger M. Current understanding of the inflammatory process in cystic fibrosis: onset and etiology. Pediatr Pulmonol 1997; 24(2):137-142; discussion 159-161.

3. Hess DR. The evidence for secretion clearance techniques. Respir Care 2001;46(11):1276-1293.

4. McCool FD, Rosen MJ. Nonpharmacologic airway clearance therapies: ACCP evidence-based clinical practice guidelines. Chest 2006; 129(1 Suppl):250S-259S.

5. Elkins MR, Jones A, van der Schans C. Positive expiratory pressure physiotherapy for airway clearance in people with cystic fibrosis. Cochrane Database Syst Rev 2006;19(2):CD003147.

6. Main E, Prasad A, van der Schans CP. Conventional chest physiotherapy compared to other airway clearance techniques for cystic fibrosis. Cochrane Database Syst Rev 2005;1:CD002011.

7. Morrison L, Agnew J. Oscillating devices for airway clearance in people with cystic fibrosis. Cochrane Database Syst Rev 2009;1: CD006842.

8. Chevallier J. Autogenic drainage. In: Lawson D, editor. Cystic fibrosis: horizons. New York: John Wiley \& Sons; 1984:235.

9. McIlwaine PM, Wong LT, Peacock D, Davidson AG. Long-term comparative trial of conventional postural drainage and percussion versus positive expiratory pressure physiotherapy in the treatment of cystic fibrosis. J Pediatr 1997;131(4):570-574. 


\section{Exhalation Tasks AND Lung Function in CF}

10. Marks JH. Airway clearance devices in cystic fibrosis. Paediatr Respir Rev 2007;8(1):17-23.

11. Hristara-Papadopoulou A, Tsanakas J, Diomou G, Papadopoulou O. Current devices of respiratory physiotherapy. Hippokratia 2008;12(4): 211-220.

12. Hardy KA, Anderson BD. Noninvasive clearance of airway secretions. Respir Care Clin N Am 1996;2(2):323-345.

13. Falk M, Kelstrup M, Andersen JB, Kinoshita T, Falk P, Støvring S, Gøthgen I. Improving the ketchup bottle method with positive expiratory pressure, PEP, in cystic fibrosis. Eur J Respir Dis 1984; 65(6):423-432.

14. Volsko TA, DiFiore J, Chatburn RL. Performance comparison of two oscillating positive expiratory pressure devices: Acapella versus Flutter. Respir Care 2003;48(2):124-130.

15. Oberwaldner B, Evans JC, Zach MS. Forced expirations against a variable resistance: a new chest physiotherapy method in cystic fibrosis. Pediatr Pulmonol 1986;2(6):358-367.

16. Stock MC, Downs JB, Gauer PK, Alster JM, Imrey PB. Prevention of postoperative pulmonary complications with CPAP, incentive spirometry, and conservative therapy. Chest 1985;87(2):151-157.

17. Basoglu OK, Atasever A, Bacakoglu F. The efficacy of incentive spirometry in patients with COPD. Respirology 2005;10(3):349-353.

18. Pellegrino R, Viegi G, Brusasco V, Crapo RO, Burgos F, Casaburi $\mathrm{R}$, et al. Interpretative strategies for lung function tests. Eur Respir J 2005;26(5):948-968.
19. Rodriguez Hortal MC, Hjelte L. Time point to perform lung function tests evaluating the effects of an airway clearance therapy session in cystic fibrosis. Respir Care 2014;59(10):1537-1541.

20. Placidi G, Cornacchia M, Polese G, Zanolla L, Assael BM, Braggion C. Chest physiotherapy with positive airway pressure: a pilot study of short-term effects on sputum clearance in patients with cystic fibrosis and severe airway obstruction. Respir Care 2006;51(10): 1145-1153.

21. Homnick DN. Making airway clearance successful. Paediatr Respir Rev 2007;8(1):40-45.

22. Chatham K, Ionescu AA, Nixon LS, Shale DJ. A short-term comparison of two methods of sputum expectoration in cystic fibrosis. Eur Respir J 2004;23(3):435-439.

23. Andersen JB, Qvist J, Kann T. Recruiting collapsed lung through collateral channels with positive end-expiratory pressure. Scand J Respir Dis 1979;60(5):260-266.

24. Darbee JC, Ohtake PJ, Grant BJ, Cerny FJ. Physiologic evidence for the efficacy of positive expiratory pressure as an airway clearance technique in patients with cystic fibrosis. Phys Ther 2004;84(6):524537.

25. Lapin C. Airway physiology, autogenic drainage, and active cycle. Respir Care 2002;47(7):778-785.

26. Delaunois L. Anatomy and physiology of collateral respiratory pathways. Eur Respir J 1989;2(9):893-904.

27. Bennett WD, Zeman KL. Effect of enhanced supramaximal flows on cough clearance. J Appl Physiol 1994;77(4):1577-1583. 